\title{
Re: Implementation of routine first trimester combined screening for pre-eclampsia: a clinical effectiveness study. (First comment on BJOG-20-0819.R2)
}

\author{
Dave Wright ${ }^{1}$ and Kypros Nicolaides ${ }^{2}$ \\ ${ }^{1}$ University of Exeter \\ ${ }^{2}$ Fetal Medicine Institute
}

July 22,2020

\section{Dear Sir}

We congratulate Dr Guy and colleagues on their paper ${ }^{1}$ which demonstrates that implementation of combined screening using the FMF algorithm ${ }^{2}$ is feasible in practice and is better than the existing NICE guidelines in prevention of preeclampsia, especially preterm preeclampsia with delivery before 34 weeks. We hope that this will lead to wider application of combined screening for prediction and prevention of preeclampsia.

The authors acknowledge that treatment with aspirin will have led to underestimation of screening performance. We would like to highlight this and emphasise the importance of accounting for the effect of aspirin when assessing predictive performance. To make the point, consider the most extreme case with $100 \%$ compliance with a treatment that prevents $100 \%$ of cases. In the screen positive group, all cases would be prevented by the treatment and classified as false positives. Adopting the same analysis presented in this paper would result in a detection rate and positive predictive value of zero regardless of performance without treatment.

In the data presented in this study, for the FMF algorithm with $99 \%$ compliance to aspirin at a dose of 150 $\mathrm{mg} /$ day and assuming $62 \%$ reduction in risk, ${ }^{3} 99 \% \times 62 \%=61.4 \%$ of cases of preterm preeclampsia would be prevented and classed as false positives. The remaining $100-61.4 \%=38.6 \%$ would be classed as true positives so the 15 cases of preterm preeclampsia which led to the detection rate of $15 / 27=55.6 \%$ represent just $38.6 \%$ of the cases of preterm preeclampsia detected. An estimate of the number detected, including those prevented by aspirin is, $15 / 0.386=39$. The estimated number of cases in total is therefore $39+12=51$, obtained by adding the false negatives $27-15=12$ to the estimated true positives. This gives a detection rate of $39 / 51=76 \%$ compared to the figure of $55.6 \%$ given in Table 2 . Applying similar calculations to the positive predictive value (i.e. proportion of women in the screen positive group who would, without aspirin, have developed preterm preeclampsia) of $9.8 \%$. This should be compared with the $3.8 \%$ presented in the paper. Applying the same arithmetic to the NICE group gives a detection rate of $41.6 \%$ and a positive predictive value of $2.4 \%$. These are much closer to the figures in Table 2 of the paper because of the relatively low compliance in the NICE group. Other measures of screening performance presented on this paper including the likelihood ratios, negative predictive value the receiver operating characteristic (ROC) curve analysis are also affected by this problem.

The arithmetic presented above is intended for illustration; for the SPREE study ${ }^{4}$ we applied Markov chain monte carlo (MCMC) methods for inferences about screening performance. These or similar methods should be applied in future studies of screening performance.

Dave Wright, ${ }^{1}$ Kypros Nicolaides ${ }^{2}$ 
1. Institute of Health Research, University of Exeter, Exeter, UK

2. Harris Birthright Research Centre for Fetal Medicine, King's College Hospital, London, UK.

\section{References}

1. Guy GP, Leslie K, Diaz Gomez D, Forenc K, Buck E, Khalil A, Thilaganathan B. Implementation of routine first trimester combined screening for pre-eclampsia: a clinical effectiveness study. BJOG2020;doi: 10.1111/1471-0528.16361.

2. O'Gorman N, Wright D, Syngelaki A, Akolekar R, Wright A, Poon LC, Nicolaides KH. Competing risks model in screening for preeclampsia by maternal factors and biomarkers at 11-13 weeks gestation. Am J Obstet Gynecol 2016;214:103.e1-103.e12.

3. Rolnik DL, Wright D, Poon LC, O'Gorman N, Syngelaki A, de Paco Matallana C, Akolekar R, Cicero S, Janga D, Singh M, Molina FS, Persico N, Jani JC, Plasencia W, Papaioannou G, Tenenbaum-Gavish K, Meiri H, Gizurarson S, Maclagan K, Nicolaides KH. Aspirin versus Placebo in Pregnancies at High Risk for Preterm Preeclampsia. N Engl J Med2017;377:613-22.

4. Tan MY, Syngelaki A, Poon LC, Rolnik DL, O'Gorman N, Delgado JL, Akolekar R, Konstantinidou L, Tsavdaridou M, Galeva S, Ajdacka U, Molina FS, Persico N, Jani JC, Plasencia W, Greco E, Papaioannou G, Wright A, Wright D, Nicolaides KH. Screening for pre-eclampsia by maternal factors and biomarkers at 11-13 weeks' gestation. Ultrasound Obstet Gynecol 2018;52:186-95. 